\title{
IMPACT OF PHOTOTHERAPY ON PLATELET COUNT IN NEONATES WITH INDIRECT HYPERBILIRUBINEMIA
}

Abd El Moktader AM (1), Ezzat GM (2), Mohamed WS (3) and Hashem NS(4).

(1)professor of Pediatrics and Neonatology, Faculty of Medicine Fayoum University.

(2)professor of Clinical and Chemical Pathology , Faculty of Medicine Fayoum university.

(3)lecturer of Pediatrics and Neonatology, Faculty of Medicine Fayoum University.

(4) Department of Paediatrics ad Neonatology, Faculty of Medicine Fayoum University.

Corresponding author: prof .Ahmed M. Abd El Moktader.

E-mail address: abdelmoktader2006@yahoo.com

Tel:01116740957

Fax: +20842168253 


\section{$\underline{\text { ABSTRACT }}$}

Background: Phototherapy though safe, is not free of side effects. Most of the studies have documented thrombocytopenia as a result of phototherapy. However, few other studies have proven the opposite effect.

Aim of work: is to evaluate the effect of phototherapy on the platelet count in full term neonates with non - hemolytic indirect hyperbilirubinemia.

Methods: a prospective cohort study which involved 120 neonates, who developed indirect hyperbilirubinaemia and required phototherapy during a period of six months from December 2018 to May 2019. Neonates having a base line platelet count of more than $150,000 / \mathrm{mm} 3$ were included .Platelet counts were performed on admission, before discontinuing phototherapy and one week later for those how developed thrombocytopenia.

Results: Out of 120 neonates included in study, 9 neonates (7.5\%) had thrombocytopenia.The majority of neonates had moderate thrombocytopenia 4 neonates

$(44,4 \%)$.Thrombocytopenia was transient and subclinical with no significant symptoms in all cases.

Conclusions: we found that there was an association of phototherapy with thrombocytopenia in hyperbilirubinemic neonates, there was a decline in platelet count after exposure to phototherapy which was highly significant in LBW babies. .However, thrombocytopenia was transient and there was no bleeding manifestation.

Keywords: Indirect hyperbilirubinaemia, Neonatal thrombocytopenia, Phototherapy, Platelet count.

\section{INTRODUCTION}

Neonatal jaundice due to unconjugated hyperperbilirubinemia is a quite common condition that affects about $60 \%$ of term and $80 \%$ of preterm infants during first week of life ${ }^{(\mathbf{1})}$.

Once unconjugated hyperbilirubinemia crosses the upper limits of physiological jaundice, it may be harmful for the brain resulting in permanent developmental delay ${ }^{(2)}$.

Treatment options available for unconjugated hyperbilirubinemia include phototherapy, exchange transfusion and IVIG. Out of these options, phototherapy which is a noninvasive technique has been used widely for the treatment of neonatal jaundice. Generally, phototherapy is very safe and may have no serious long-term effects on neonates ${ }^{(3)}$.

Phototherapy though safe, is not free of side effects, the following adverse effects and complications have been noted: increase insensible water loss, loose stools, retinal damage, bronze baby syndrome, gonadal toxicity, impaired maternalinfant interaction, hypocalcemia and skin rash.The combination of hyperbilirubinemia and phototherapy can produce DNAstrand breakage and other effects on cellular genetic material ${ }^{(4)}$.

Although most of the studies have documented thrombocytopenia as a result of phototherapy but, few other studies have proven the opposite effect of phototherapy on the platelet count. So, the ultimate effect of phototherapy on platelet count still needs to be investigated further in various clinical settings ${ }^{(5)}$.

\section{Patients ANd Methods}

This study included 120 full term neonates admitted to the neonatal intensive care units (NICU) at Fayoum university hospital with indirect hyperbilirubinemia.

Patients:
Inclusion criteria:

1) Age: 2 to 28 days.

2)full term babies of both gender.

3)Delivered vaginally or by cesarean section.

4) Indirect hyperbilirubinemia requiring phototherapy for 48 hours or more according to guidelines of phototherapy in hospitalized infants born at a gestational age of $\geq 35$-week (American Academy of Pediatrics, 2004).

5) A baseline platelet count of more than $150,000 / \mathrm{mm} 3$ before starting phototherapy.

Exclusion criteria:

1)Haemolysis.

2)ABO or Rh incompatibility.

3)Direct hyperbilirubinaemia.

4)Sepsis.

5)Asphyxia.

6)Anti-platelet drugs given to baby or mother.

7)Haemangioma

8)Other congenital anomalies were excluded.

All neonates in this study were subjected to the following:

1. history taking:full history

2.Clinical examination of the studied newborns_complete physical and systemic examination

3.Investigations

Laboratory assessment of the following

1)Complete blood count with reticulocyte count to exclude hemolysis.

2) $\mathrm{ABO}$ and $\mathrm{Rh} \mathrm{D}$ blood grouping.

3) Total and direct serum bilirubin.

4) Platelet count on admission and before discontinuing 5)phototherapy, Neonates showed a fall of platelet count were recorded, Then followed up after one week to asses any change in platelet count if present.

\section{Method:}

EDTA anticoagulated venous blood samples were collected and sent for complete blood count including platelet count and blood group, and clotted venous blood samples were collected and sent for total bilirubin and direct bilirubin.

\section{Statistical Methods}

The collected data were organized, tabulated and statistically analyzed using SPSS software statistical computer package version 22 (SPSS Inc, USA). For quantitative data, the mean and standard deviation (SD) were calculated. Paired t-test or Repeated measures ANOVA was performed to compare between values of platelets count as different times. Independent t-test was used in comparing between groups of

thrombocytopenia vs. normal and between neonates with birth weight $<2.5 \mathrm{vs}$. $\geq 2.5 \mathrm{~kg}$ as regards platelets count. Qualitative data were presented as number and percentages and Chi-squared test or Fisher exact test, when appropriate, was used as a test of significance.For interpretation of results of tests of significance, significance was adopted at $\mathrm{P}<0.05$.

\section{Ethical Consideration}

This study was reviewed and approved by the Faculty of Medicine Research Ethical Committee. It was conducted after explaining the study objectives and confidentiality was expressed to the mothers of study neonates. Verbal consent was obtained from participating mothers before data collection. Each participant had the right not to participate in the study. 


\section{RESULTS}

Table (1) : Incidence of thrombocytopenia.

\begin{tabular}{|c|c|c|}
\hline $\begin{array}{c}\text { Incidence of } \\
\text { thrombocytopenia }\end{array}$ & $\mathrm{N}(\mathbf{1 2 0})$ & $\%$ \\
\hline Yes & 9 & $\mathbf{7 . 5 \%}$ \\
\hline No & 111 & $\mathbf{9 2 . 5 \%}$ \\
\hline
\end{tabular}

Table (4) and Figure (5) illustrated that $7.5 \%$ of total neonates involved in the study had thrombocytopenia on discontinuing phototherapy out of which 3 (33.3\%), 4 (44.4)\% and 2 (22.2)\% of infants had mild, moderate and severe thrombocytopenia respectively.

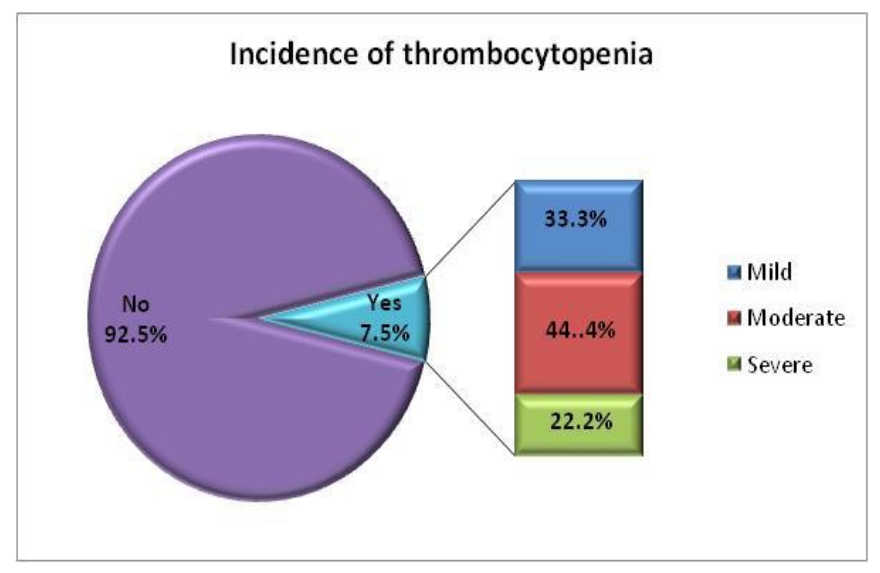

Mild, moderate and severe thrombocytopenia are defined as platelet counts between 100,000-150,000/mm3; 50,000$100,000 / \mathrm{mm} 3 ;<50,000 / \mathrm{mm} 3$, respectively (Gregory et al., 2012).

Figure (1): Incidence of thrombocytopenia.

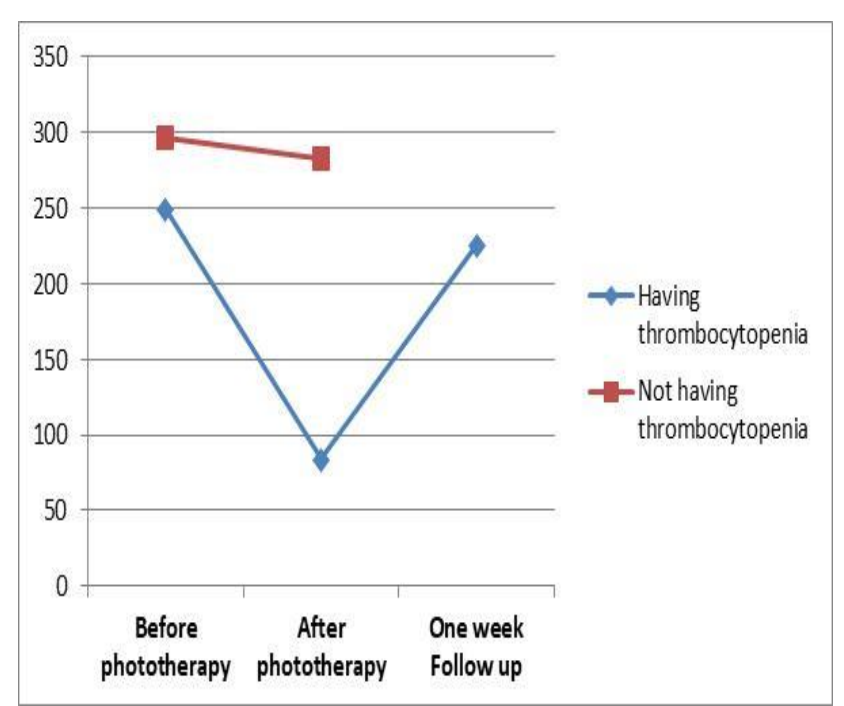

Figure (6): The mean platelet counts before and after phototherapy in thrombocytopenic group and non-thrombocytopenic group.

Table (8) and Figure (8): Relation between weight and thrombocytopenia.

\begin{tabular}{|c|c|c|c|c|c|}
\hline \multirow[t]{2}{*}{ Variable } & \multicolumn{2}{|c|}{$\begin{array}{c}\text { Group I } \\
(\mathrm{N}=9)\end{array}$} & \multicolumn{2}{|c|}{$\begin{array}{c}\text { Group II } \\
(\mathrm{N}=111)\end{array}$} & \multirow[t]{2}{*}{$P$-value } \\
\hline & $\mathbf{N}$ & $\%$ & $\mathbf{N}$ & $\%$ & \\
\hline \multicolumn{6}{|l|}{ Weight } \\
\hline $\begin{array}{l}<2.5 \mathrm{~kg} \\
(\mathrm{~N}=21)\end{array}$ & 7 & $33.3 \%$ & 14 & $66.7 \%$ & \multirow[t]{2}{*}{$\begin{array}{c}<0.0001 \\
(\mathrm{HS})\end{array}$} \\
\hline $\begin{array}{l}\geq 2.5 \mathrm{~kg} \\
(\mathrm{~N}=99)\end{array}$ & 2 & $2 \%$ & 97 & $98 \%$ & \\
\hline
\end{tabular}

HS: Highly significant

Group I: neonates having thrombocytopenia.

Group II: neonates not having thrombocytopenia.

Table (8) and Figure (8) illustrated highly statistically significant positive association between weight and development of thrombocytopenia with p-value $<0.0001$. Incidence of

thrombocytopenia was higher in low birth weight neonates $<2.5 \mathrm{~kg}$ than those with appropriate weight for age $\geq 2.5 \mathrm{~kg}$.

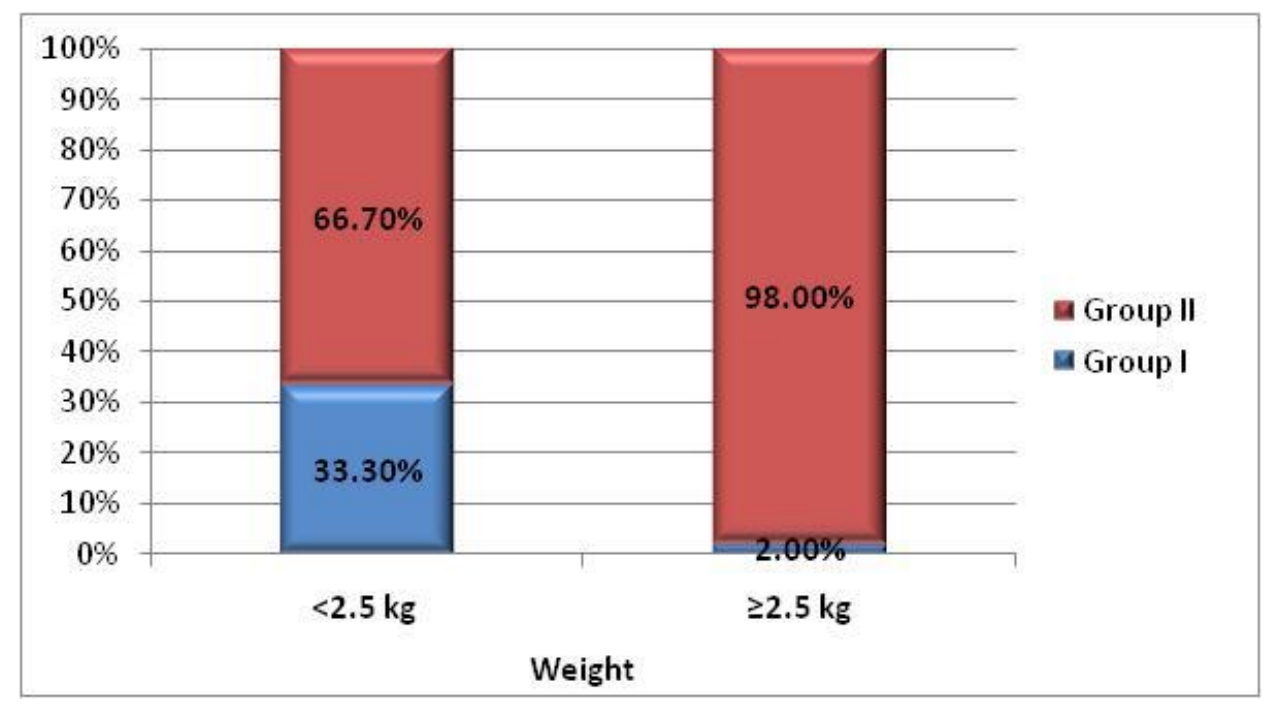

Figure (8): Incidence of thrombocytopenia among low birth weight and appropriate for age neonates.

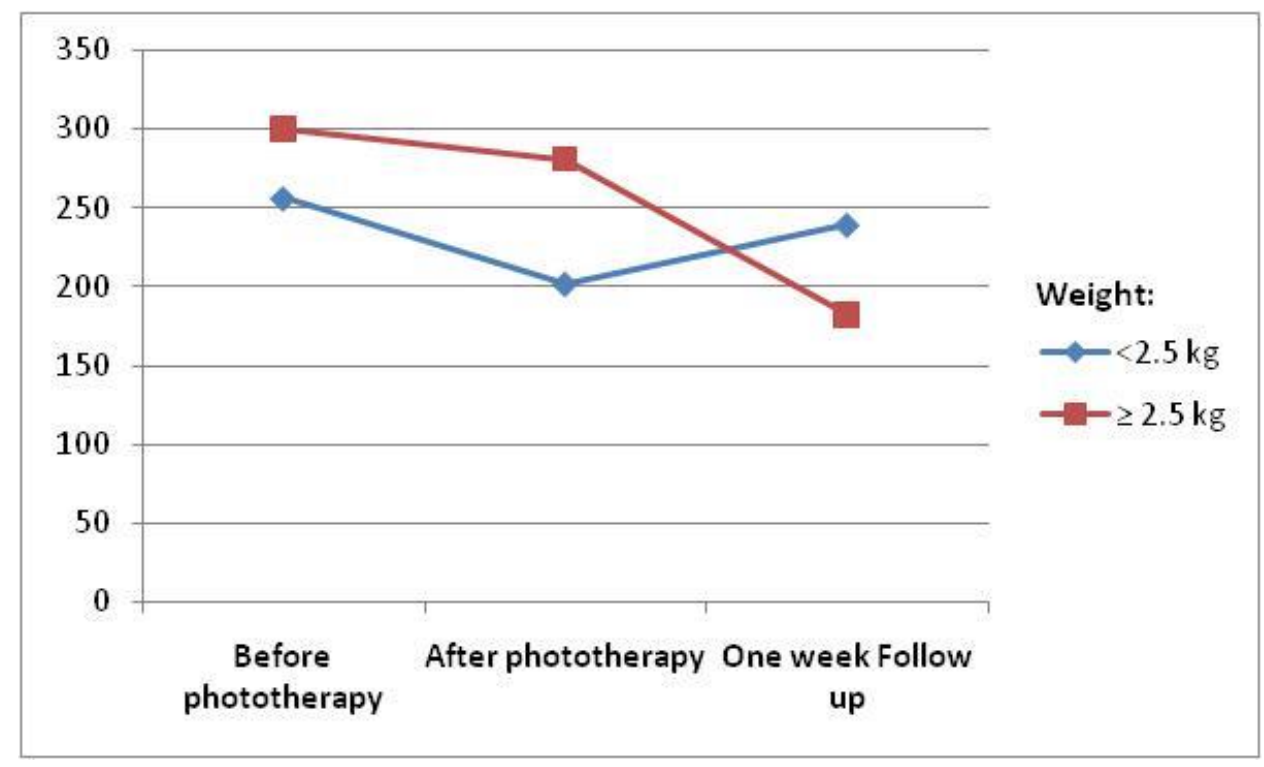

Figure (9): The mean platelets counts in relation to weight.

Table (10) Figure (10-11-12): The comparison of serum bilirubin levels, duration of phototherapy and type of phototherapy in relation to thrombocytopenia.

\begin{tabular}{|c|c|c|c|c|c|}
\hline \multirow[t]{2}{*}{ Variable } & \multicolumn{2}{|c|}{$\begin{array}{c}\text { Group I } \\
(\mathbf{N}=9)\end{array}$} & \multicolumn{2}{|c|}{$\begin{array}{l}\text { Group II } \\
(\mathbf{N}=111)\end{array}$} & \multirow[t]{2}{*}{ P-value } \\
\hline & $\mathbf{N}$ & $\%$ & & & \\
\hline \multicolumn{6}{|c|}{ Serum total bilirubin(mg /dL) } \\
\hline$\leq 18$ & 4 & $6.8 \%$ & 55 & $93.2 \%$ & \multirow{2}{*}{$\begin{array}{l}1.000 \\
(\mathrm{NS})\end{array}$} \\
\hline$>18$ & 5 & $8.2 \%$ & 56 & $91.8 \%$ & \\
\hline \multicolumn{6}{|c|}{ Photo duration(hours) } \\
\hline$\leq 48$ hours & 3 & $4.3 \%$ & 66 & $95.7 \%$ & \multirow{2}{*}{$\begin{array}{l}0.167 \\
(\mathrm{NS}) \\
\end{array}$} \\
\hline$>48$ hours & 6 & $11.8 \%$ & 45 & $88.2 \%$ & \\
\hline \multicolumn{6}{|c|}{ Type of photo therapy } \\
\hline $\begin{array}{l}\text { Single surface } \\
\text { photo }\end{array}$ & 4 & $7.3 \%$ & 51 & $92.7 \%$ & \multirow[t]{2}{*}{$\begin{array}{l}1.000 \\
(\mathrm{NS})\end{array}$} \\
\hline $\begin{array}{l}\text { Double } \\
\text { surface photo }\end{array}$ & 5 & $7.7 \%$ & 60 & $92.3 \%$ & \\
\hline
\end{tabular}

Table (10) and Figure (10-11-12) illustrated that Incidence of thrombocytopenia was higher in neonates with serum bilirubin $>18(\mathrm{mg} / \mathrm{dL})$ than in those with serum bilirubin $\leq 18(\mathrm{mg} / \mathrm{dL})$, it was higher in neonates exposed to phototherapy $>48$ hours than in those exposed to phototherapy $\leq 48$ hours, it was nearly similar among neonates exposed to single surface phototherapy and those exposed 
to double surface phototherapy. There was no statistically significant difference $\mathrm{p}$-value in the incidence of thrombocytopenia based on bilirubin levels, duration of phototherapy and type of phototherapy $p=1.000,0.167$ and 1.000 respectively.

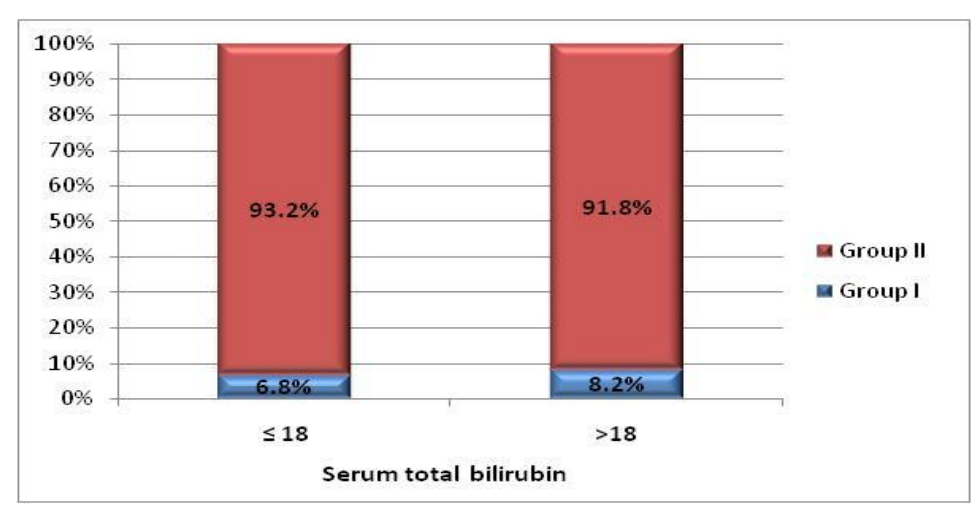

Figure (10) ): The incidence of thrombocytopenia among neonates with serum bilirubin $>18(\mathrm{mg} / \mathrm{dL})$ and those with serum bilirubin $\leq$ $18(\mathrm{mg} / \mathrm{dL})$.

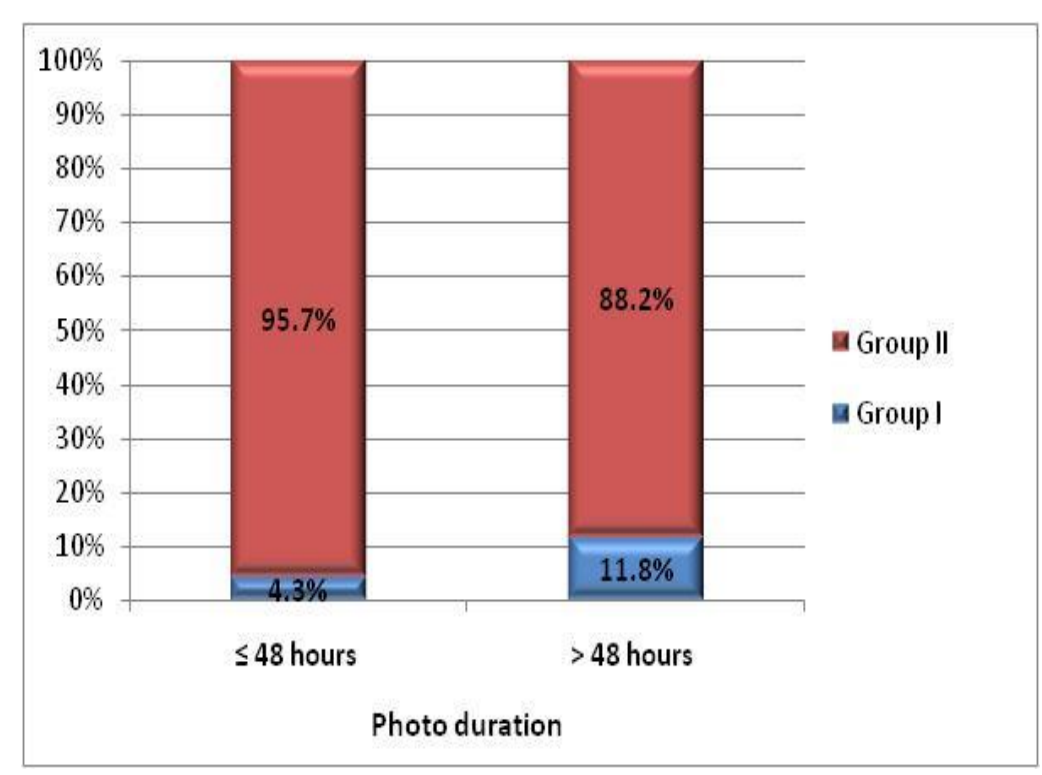

Figure (11): The incidence of thrombocytopenia among neonates with phototherapy duration $>48$ hours and those with phototherapy duration $\leq 48$ hours.

\section{DISCUSSION}

Thrombocytopenia as a side effect following exposure to phototherapy was documented by our study.The overall incidence of thrombocytopenia was $7.5 \%$.this came in agreement with Khera and Gupta, 2011 ${ }^{(5)}$ and Shah et al., $2019^{(6)}$ who showed that phototherapy was complicated by thrombocytopenia in $35 \%$ and $45.6 \%$ of neonates who received phototherapy.In disagreement with our study, the study done by Monsef et al ., 2011 ${ }^{(7)}$ which reported that there was an increase in the platelet count after phototherapy

As regarding to severity of thrombocytopenia, our study showed that 3 neonates (33.3\%), 4 neonates $(44.4 \%)$ and 2 neonates $(22.2 \%)$ of neonates who developed thrombocytopenia had mild, moderate and severe thrombocytopenia respectively. In disagreement with our study, the study of Khera and Gupta, 2011 ${ }^{(5)}$ showed that majority of neonates had mild thrombocytopenia (74\%), moderate and severe thrombocytopenia was seen in $23 \%$ and $3 \%$ cases respectively.

In our study, the neonatal age with starting phototherapy ranged between 2 and 8 days, the incidence of thrombocytopenia was higher with starting the phototherapy within 72 hours of birth than beyond that, but it was not statistically significant $\mathrm{p}=0.780$. This came in agreement with the study conducted by Shah et al., $2019^{(\boldsymbol{6})}$ that revealed that the incidence of thrombocytopenia was higher with starting the

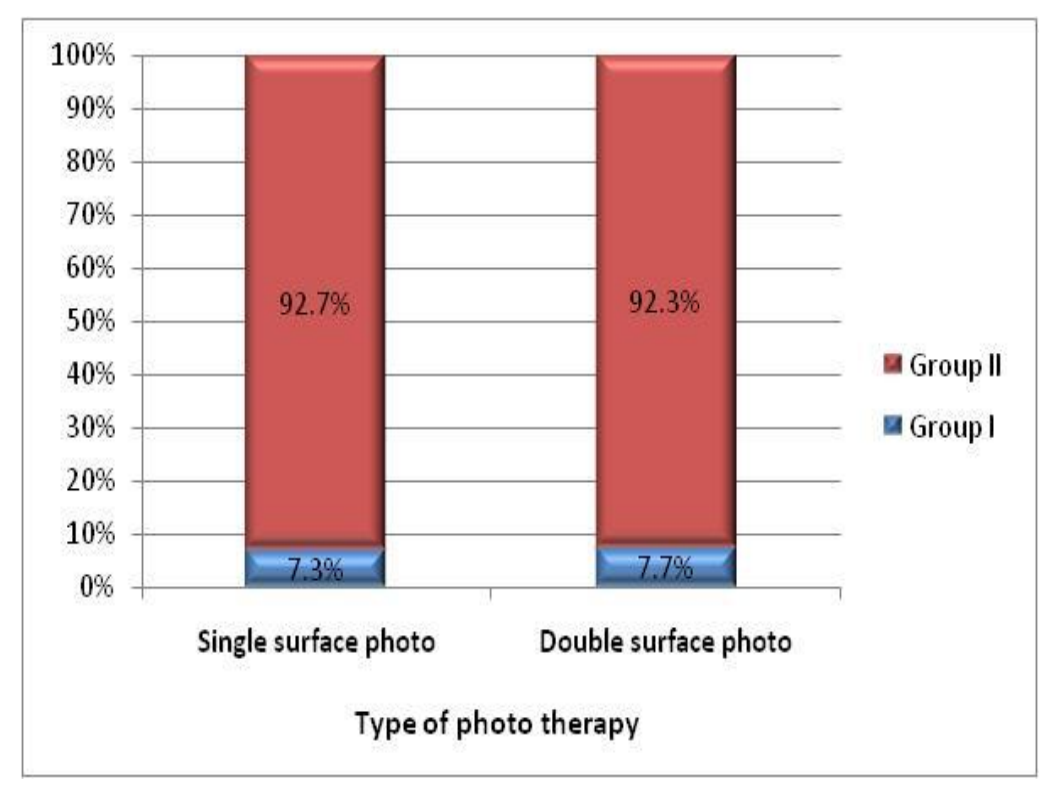

Figure (12): The incidence of thrombocytopenia among neonates exposed to single surface phototherapy and those exposed to double surface phototherapy.

phototherapy within 72 hours of birth than beyond ; however, it was statistically significant $(\mathrm{p}<0.05)$.

The incidence of thrombocytopenia was higher in low birth weight neonates than those with appropriate weight for age which was statistically significant $(p=<0.0001)$.this came in agreement with the study performed by Shah et al., $2019^{(6)}$ that revealed that The incidence of thrombocytopenia was higher in low birth weight neonates than those with appropriate weight for age but it was not statistically significant $(\mathrm{p}>0.05)$. In disagreement with our study, the study done by Khera and

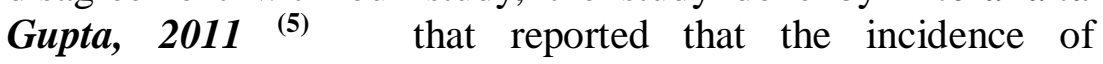
thrombocytopenia was higher in neonates weighing $>2.5 \mathrm{Kg}$ $(\mathrm{p}=0.11)$.

The Incidence of thrombocytopenia was higher in neonates with serum bilirubin $>18(\mathrm{mg} / \mathrm{dL})$ than in those with serum bilirubin $\leq 18(\mathrm{mg} / \mathrm{dL})$ which was not statistically significant $(\mathrm{p}=1.000)$. In agreement with our study, the study conducted by Khera and Gupta, $2011^{(5)}$ that revealed that the incidence of thrombocytopenia was higher in neonates with serum bilirubin $>18(\mathrm{mg} / \mathrm{dL})$ than in those with serum bilirubin $\leq 18(\mathrm{mg} / \mathrm{dL})$, but it was not statistically significant $(\mathrm{p}=0.11)$.

The incidence of thrombocytopenia was higher in neonates exposed to phototherapy $>48$ hours than in those exposed to phototherapy $\leq 48$ hours which was not clinically significant $(\mathrm{p}=0.167)$.this was in agreement with the study conducted by Khera and Gupta, 2011 that revealed that the incidence of 
thrombocytopenia was higher in neonates exposed to phototherapy $>48$ hours and it was not of clinical significance $(\mathrm{p}=0.44)$.

The incidence of thrombocytopenia was higher in neonates receiving DSPT as compared to those who received SSPT, but there was no statistically significant difference in the incidence of thrombocytopenia based on type of phototherapy $\mathrm{p}(=1.000)$ which was In agreement with the study conducted by Shah $\boldsymbol{e t}$ al., $2019^{(6)}$ and Khera and Gupta, $2011^{(5)}$ which revealed that the incidence of thrombocytopenia was higher in neonates receiving double surface Phototherapy (DSPT), however it was not statistically significant $(\mathrm{p}>0.05)$ and $(\mathrm{p}=0.45$ )respectively.

\section{CONCLUSION}

From our study we concluded there was a decline in platelet count after exposure to phototherapy which was highly significant in LBW babies.

thrombocytopenia was transient, subclinical with no significant symptoms in all cases.

Being transient and subclinical, extensive investigations for thrombocytopenia following phototherapy may be delayed in these neonates.

\section{RECOMMENDATION}

Phototherapy treatment should be initiated based on the standard guidelines. Unnecessary use and prolongation of phototherapy should be avoided considering the possible side effects.

\section{REFERENCES}

1. Shapiro SM, Riordan SM. Review of bilirubin neurotoxicity II (2019): preventing and treating acute bilirubin encephalopathy and kernicterus spectrum disorders. Pediatric Research;3:1-6.

2. Helal NF, Ghany EA, Abuelhamd WA, Alradem AY (2019): Characteristics and outcome of newborn admitted with acute bilirubin encephalopathy to a tertiary neonatal intensive care unit. World Journal of Pediatrics. Feb 4; 15(1):42-8.

3. Cayabyab R, Ramanathan $\mathbf{R}$ (2019):High unbound bilirubin for age: a neurotoxin with major effects on the developing brain. Pediatric research; 85(2):183-90.

4. Amandito R, Rohsiswatmo R, Carolina E, Maulida R, Kresnawati W, Malik A (2019): Profiling of UGT1A1*6, $\mathrm{UGT} 1 \mathrm{~A} 1 * 60$, UGT1A $1 * 93$, and UGT1A $1 * 28$ polymorphisms in indonesian neonates with hyperbilirubinemia using multiplex PCR sequencing. Front Pediatr;7:328. doi: 10.3389/fped.2019.00328.

5. Khera S, Gupta R (2011): Incidence of thrombocytopenia following phototherapy in hyperbilirubinemic neonates. Med J Armed Forces India; 67 (04) 329-332.

6. Shah MH, Vedula R, Roshan R (2019): Incidence of thrombocytopenia in neonates receiving phototherapy for indirect hyperbilirubinemia: a prospective cohort study. Int J Res Med Sci; 7:3505-9.

7. Monsef A, Eghbalian F (2011): Does conventional phototherapy have any effect on platelet count in full term neonates with indirect hyperbilirubinemia. Sci Res; 3(12):709-11. 14. 